\title{
NCPDP Strength Form Terminology
}

National Cancer Institute

\section{Source}

National Cancer Institute. NCPDP Strength Form Terminology. NCI Thesaurus. Code C89508.

A terminology subset for NCPDP that contains concepts that qualify the strength and strength unit of measure associated with the prescribed product (e.g. Amoxicillin $250 \mathrm{mg}$ Tablet, Albuterol HFA 17 gram Inhaler, Albuterol HFA 90 mcg [implied per actuation] Inhaler, Cefaclor 250 MG/5ML Suspension, Fentanyl 12 mcg/hr Patch, Epinephrine 0.3 mg [implied per dose] Auto-Injector, T imolol 0.25\% Ophthalmic Drops, Sprintec 28 Day Pack, Hydrocortisone 1\% Ointment). 